заместитель директора

Санкт-Петербургского филиала

федерального государственного унитарного

предприятия «Экспериментально-производственные мастерские» Федерального медико-биологического агентства России - специального конструкторскотехнического бюро «Биофизприбор»

\section{ОРГАНИЗАЦИОННО-ЭКОНОМИЧЕСКИЙ МЕХАНИЗМ ИННОВАЦИОННОГО РАЗВИТИЯ И ЛОКАЛИЗАЦИИ ПРОИЗВОДСТВА ТОВАРОВ И УСЛУГ ДЛЯ НУЖД ЗДРАВООХРАНЕНИЯ}

\section{Аннотация:}

Введено понятие организационно-экономического механизма инновационного развития производства товаров и услуг для нужд здравоохранения как системы отношений и обеспечивающих их институтов, направленной на создание и распространение инноваций в данной сфрере. Субъектами отношений выступают исполнительные органы государственной власти; инвесторы; отечественные предприятия медицинской и фармацевтической промышленности; зарубежные корпорации; медицинские, научно-исследовательские, образовательные организации; профессиональные ассоциации. Выявлены проблемы локализации выпуска фармацевтической продукции и медицинских изделий и основные пути их решения в интересах повышения доступности инновационных медицинских технологий для населения. Определены аспекты доступности инновационных медицинских технологий для граждан, такие как физическая, ценовая и географическая доступность, пригодность, приемлемость и качество. Для примера оценены потребности в локализации производства препаратов для лечения ВИЧинфицированных. Сделан акцент на целесообразности разработки и создания фармацевтических субстанций и инновационных лекарственных средств.

Ключевые слова:

здравоохранение, инновационная деятельность, медицинские изделия, медицинская и фармацевтическая наука и промышленность, производство товаров и услуг, фармацевтическая продукция.
Deputy Director, St.-Petersburg branch, Federal State Unitary Enterprise Experimental Industrial Workshops of the Federal Medical and Biological Agency Special Design Technological Bureau Biofizpribor

\section{ORGANIZATIONAL ECONOMIC MECHANISM OF INNOVATIVE DEVELOPMENT AND LOCALIZATION OF HEALTHCARE GOODS AND SERVICES PRODUCTION}

Keywords: healthcare, innovation activity, medical products, medical and pharmaceutical science and industry, production of goods and services, pharmaceuticals.

The author introduced the notion of the organizational economic mechanism for the innovative development of healthcare goods and services production as a system of relations and institutions aimed at creating and disseminating innovations in this field. The subjects of relations are executive authorities, investors, domestic enterprises of the medical and pharmaceutical industry, foreign corporations, medical, research, and educational organizations, professional associations. The problems concerning production localization for pharmaceutical and medical products and the main ways to solve them are identified in order to raise availability of innovative medical technologies for the population. The study determines the aspects of accessibility of innovative medical technologies for the population which include physical, price, and geographic availability, suitability, acceptability, and quality. As an example, the author assessed the need to localize the production of drugs for the treatment of HIV-infected patients. The paper focuses on the feasibility of developing and manufacturing pharmaceutical substances and innovative medicines.

\title{
Введение
}

Инновационная модель развития медицинской и фрармацевтической науки и промышленности, определенная в государственных документах стратегического развития экономики страны [1], предполагает создание условий для развития инновационного бизнеса, совершенствование государственного управления фрормированием инновационной среды, привлечение отечественных и зарубежных инвестиций в экономику России, развитие высоких технологий и экономики знаний. Для производства импортозамещающих и импортоопережающих медицинских изделий и фармацевтической продукции совершенствование системы научных исследований в здравоохранении, медицине и фармацевтике является значимым фактором не только повышения качества и доступности медицинской помощи, сохранения и укрепления здоровья населения, но и обеспечения экономической и социальной безопасности РФ [2].

Государственная программа развития фрармацевтической и медицинской промышленности [3] направлена на внедрение инноваций при выпуске медицинских изделий и лекарственных средств, формирование инновационного, производственного и технологического потенциала медицинской и фармацевтической промышленности. Для решения поставленных задач необходим 
организационно-экономический механизм инновационного развития выпуска товаров и услуг для здравоохранения.

Понятие организационно-экономического механизма инновационного развития. Разработанная в конце XX в. академиком Л.И. Абалкиным категория хозяйственного механизма устойчиво вошла в научный оборот и породила родственные понятия, такие как экономический, организационный, финансовый, организационно-экономический механизмы [4]. В последующие годы эти категории и их отдельные аспекты широко обсуждались в многочисленных научных публикациях. В наиболее конспективном виде генезис и разные взгляды на эту проблему представлены, например, в работах [5]. Достаточно полное, на наш взгляд, определение существует применительно к проектному управлению [6].

В контексте настоящего исследования организационно-экономический механизм понимается как система отношений и обеспечивающих их институтов, направленная на создание и распространение инноваций в сфере производства товаров и услуг для здравоохранения. В качестве субъектов отношений выступают исполнительные органы государственной власти; инвесторы; отечественные предприятия медицинской и фармацевтической промышленности; зарубежные корпорации; медицинские, научно-исследовательские, образовательные организации; профессиональные ассоциации.

В условиях курса на импортозамещение и импортоопережение изучение важнейших институтов, регулирующих отношения при разработке и выпуске товаров и услуг для здравоохранения, является важной научной задачей. Развитие этих институтов выступает ключевым направлением не только поддержания конкурентоспособности отечественной фармацевтической и медицинской промышленности на международных рынках, но и устойчивого социального развития страны за счет обеспечения доступности инновационных медицинских технологий для широких слоев населения.

Проблемы локализации производства медицинских изделий и основные пути их решения в интересах повышения доступности инновационных медицинских технологий для населения. Снижение доступности медицинских технологий, обеспечиваемых за счет применения прежде всего дорогостоящего медицинского оборудования и инновационных лекарственных препаратов, может быть обусловлено следующими причинами:

- ограниченное внедрение международных стандартов и процедур сертификации для продвижения качественной современной продукции;

- недостаточное развитие механизмов ограничения недобросовестной конкуренции поставщиков медицинских изделий и фармацевтической продукции, обеспечения прозрачности закупок и ценообразования;

- недостаточное финансирование, необходимое для постоянного обслуживания и использования медицинского оборудования в течение всего срока его службы;

- отсутствие каналов распространения информации об инновационных медицинских технологиях, позволяющих выбирать и безопасно использовать их;

- отсутствие партнерства и способов взаимодействия между научным сообществом, органами государственной власти и бизнесом для распространения инноваций на целевых рынках медицинских изделий и фармацевтической продукции.

Необходимо различать следующие аспекты доступности медицинских технологий.

Физическая доступность определяется тем, можно ли найти необходимое медицинское изделие и фармацевтическую продукцию на национальных целевых рынках. Она также может означать, что медицинские технологии доступны в медицинских учреждениях и пригодны к использованию медицинскими работниками для лечения пациентов.

Ценовая доступность обусловлена тем, насколько получатели медицинского обслуживания или продукта в состоянии заплатить за его применение.

Географическая доступность относится к возможностям для граждан использовать медицинские технологии в случае необходимости. Другими словами, она определяется тем, имеют ли домашние хозяйства или отдельные лица доступ в медицинские учреждения, обеспечивающие реализацию тех или иных медицинских технологий для того или иного состояния здоровья.

Понятие пригодности относится к медицинским методам, процедурам, методикам, которые должны быть научно обоснованы, адаптированы к местным потребностям, приемлемы как для пациентов, так и для медицинского персонала, обеспечены ресурсами, которые может позволить себе общество. При определении пригодности нужно учитывать имеющиеся инфраструктуру, потребности населения и возможности фринансирования.

Приемлемость медицинских технологий обусловлена отношением домашних хозяйств или индивидуумов к их использованию и ожиданиями от их внедрения. В частности, она определяется тем, являются ли эти технологии социально и культурно приемлемыми для удовлетворения местных потребностей. 
Качество обусловлено тем, соответствуют ли медицинские технологии стандартам эффективного и безопасного применения.

Фактически перечисленные аспекты доступности зависят от развития инновационных технологий в сфере разработки, создания и использования медицинских изделий и фрармацевтической продукции. Также технологии содержат решения, которые ранее не существовали или не были доступны в России, являются более безопасными и (или) более простыми в применении, чем ранние решения, или более экономически эффрективными. Под передачей технологии следует понимать передачу технической информации, неявных ноу-хау, навыков работы, технических материалов или оборудования, совместно или их отдельных элементов, в целях обеспечения технологических или производственных возможностей получателей.

В фармацевтической и медицинской индустрии исторически ведущими были развитые государства, несмотря на то что глобальное бремя болезней обычно более выражено в странах с низкими и средними доходами. Поэтому Всемирная организация здравоохранения всегда выражала обеспокоенность [7], что центральные производители фармацевтической продукции и медицинских изделий не учитывают потребности широких слоев населения, а территории с низким платежеспособным спросом не могут обеспечить отдачу от инвестиций. Следствием этого является сокращение ассортимента товаров для стран с низкими доходами вместо разработки продукции, обеспечивающей потребности их граждан.

Указанные проблемы начали решать в последние десятилетия. Крупные производители медицинской техники и фармацевтической продукции стали размещать производство на территориях с более низким уровнем жизни или налаживать партнерские отношения с местными производителями. Подобные связи в ряде случаев обеспечивали передачу технологий, однако сфера национальных исследований и разработок не развивалась. Также возникали ситуации, когда производители в менее развитых государствах выпускали медицинские товары и фармацевтическую продукцию, которые могли конкурировать с иностранным импортом с точки зрения функциональности и цены. Появились новые бизнес-модели, поскольку новаторы в странах с более низким доходом были ориентированы на снижение затрат и поиск творческих путей для преодоления фринансовых барьеров, а производители в развитых государствах начали создавать доступные устройства для обеспечения своей доли на развивающихся рынках.

Локализованные изделия (с высокой долей добавленной стоимости во внутренней экономике) обычно имеют более низкую цену, чем аналогичные импортные товары. Локализация производства также обеспечивает развитие инфраструктуры системы здравоохранения и, как следствие, экономическую безопасность системы национального здравоохранения. Важно также отметить потенциальные угрозы, связанные с локализацией производства. В том случае, если объем выпуска недостаточен для значимого снижения розничных цен и не согласуется с реальными потребностями здравоохранения, развитие локализованного производства нецелесообразно, поскольку может вызвать необоснованное сокращение ресурсов на более важных направлениях.

Новые медицинские технологии постепенно становятся все более специализированными, сложными, менее инвазивными и более экономичными. Недорогие инновации удешевляют медицинские технологии и делают их доступными для больших групп населения.

Локализованное производство должно быть направлено на повышение результативности национального здравоохранения, учитывать региональные потребности, гарантировать качество, приемлемость и пригодность медицинских технологий. Локализация может обеспечивать разные уровни добавленной стоимости от сборки изделия из готовых компонентов до полного цикла производства. Примечательно, что некоторые патентообладатели медицинских устройств раскрывают детали своих изобретений в патентных документах. Это может помочь передаче технологий, поскольку позволяет другим компаниям основываться на данных инструкциях и создавать собственные продукты. В отличие от фрармацевтических препаратов, как правило, можно изобретать новые медицинские изделия на основе существующих патентов.

Услуги в области научных исследований и разработок, в частности создания фрармацевтических субстанций и инновационных лекарственных средств, в значительных объемах финансируются в России в рамках госпрограмм [8]. Несомненно, государственные инвестиции в исследования и производство товаров и услуг для нужд здравоохранения являются значимым фактором инновационного развития данной области [9]. Однако деятельность на основе бюджетного фринансирования сопряжена с такими проблемами, как меньшая экономическая эфффективность по сравнению с частными инвестициями, низкий уровень реальной конкуренции среди возможных исполнителей государственных контрактов [10].

Следующие организационные проблемы сдерживают локализацию производства медицинских изделий и инновационной фрармацевтической продукции:

- высокие затраты на начальных этапах создания производства;

- низкая доступность фринансирования на начальных этапах; 
- ограниченное понимание жизненного цикла бизнеса медицинских технологий среди инвесторов и кредиторов;

- слабые производственные мощности и неопределенные рынки;

- неблагоприятная среда (политическая, экономическая, социальная, технологическая и правовая) для местных производителей для максимизации прибыли за счет масштаба.

Целесообразна реализация следующих мер для развития производства медицинских изделий и фармацевтической продукции внутри страны.

1. Выявление наиболее востребованных в медицинской практике устройств и препаратов, так как инвесторы заинтересованы вкладывать средства в основные технологические области, которые обеспечивают высокий спрос и более широкий рынок.

2. Подготовка стандартов и технических спецификаций. Лица, принимающие решения, должны получать информацию о минимальных требованиях к изделиям и препаратам. Это побудит производителей соблюдать спецификации и стандарты с ранних этапов разработки.

3. Обеспечение прозрачности нормативно-правовой базы и гармонизации ее с международными стандартами. Поскольку медицинские изделия и фармацевтическая продукция должны быть безопасными и эффективными, важны правила и стандарты в производстве, распространении и экспорте технологий. Могут быть реализованы простые и прозрачные правила, которые также помогают упростить сертификацию изделий.

4. Ускорение коммерциализации результатов исследований и разработок за счет более тесного взаимодействия и обмена информацией между разработчиками, бизнесом, потребителями в лице медицинских организаций и населения, создания центров поддержки инноваций [11]. Одной из мер успеха для отечественного производства медицинских изделий и фармацевтической продукции является то, что имеющиеся технологии используются для удовлетворения намеченных потребностей в области здравоохранения. Тем не менее информация о технологиях может быть ограничена, что побуждает лиц, принимающих решения, выбирать товары известных международных производителей, а не местных. Увеличивая поддержку местных профессиональных сетей для обмена знаниями о безопасных, доступных и эффективных для удовлетворения потребностей граждан технологиях, можно повысить информированность об их эффективности.

Примером необходимости локализации фармацевтического производства для обеспечения социальной безопасности является производство препаратов для лечения ВИЧ. По данным ВО3 [12], в конце 2015 г. в мире насчитывалось около 36,7 млн ВИЧ-инфицированных. В 2016 г. 19,5 млн ВИЧ-инфицированных (более 50 \% зарегистрированных больных) получали антиретровирусную терапию; 7 из 10 беременных женщин, живущих с ВИЧ, проходят лечение. В развитых странах требуемую медицинскую помощь получают почти 100 \% зарегистрированных больных. По словам руководителя Федерального научно-методического центра по профилактике и борьбе со СПИДом академика В.В. Покровского, «сейчас антиретровирусную терапию из-за нехватки финансирования получают только 260 тысяч зарегистрированных ВИЧ-позитивных россиян из 850 тысяч» [13]. В России в условиях практически генерализованной эпидемии ВИЧ/СПИД [14] и ограниченных возможностей финансирования лечения инфицированных создание и выпуск отечественных инновационных антиретровирусных препаратов позволит существенно повысить обеспеченность больных лекарствами.

Открытые данные Минздрава, доступные на сегодняшний день на сайте ЕМИСС, свидетельствуют о возрастании доли ВИЧ-инфицированных, охваченных лечением (таблица 1) за счет производства отечественных препаратов [15], и необходимости дальнейшего развития отечественного производства.

\section{Таблица 1 - Динамика охвата ВИЧ-инфицированных и больных СПИДом} антиретровирусной терапией, \% [16]

\begin{tabular}{|c|c|c|c|}
\hline Показатель & 2012 & 2013 & 2014 \\
\hline $\begin{array}{l}\text { Доля ВИЧ-инфицированных лиц, получающих антиретровирусную терапию, } \\
\text { от числа состоящих на диспансерном учете }\end{array}$ & 28,6 & 32,9 & 36,4 \\
\hline $\begin{array}{l}\text { Доля ВИЧ-инфицированных лиц, состоящих на диспансерном учете, от } \\
\text { числа выявленных }\end{array}$ & 65,8 & 64,8 & 66,0 \\
\hline $\begin{array}{l}\text { Охват пар «мать - дитя» химиопрофилактикой в соответствии с действую- } \\
\text { щими стандартами }\end{array}$ & 85,7 & 85,2 & 84,2 \\
\hline
\end{tabular}

\section{Заключение}

Целесообразна реализация следующих мер, направленных на развитие организационноэкономического механизма инновационного развития и локализации производства товаров и услуг для нужд здравоохранения: 
- привлечение дополнительных частных инвестиций в процесс исследования и разработки в области создания новых медицинских изделий и фрармацевтической продукции за счет льготного налогообложения;

- обеспечение эффективности и безопасности медицинских изделий и фармацевтической продукции на уровне, сопоставимом с таковым брендированных товаров, за счет стандартизации и сертификации;

- коммерциализация с участием государства результатов исследований и разработок, выполненных государственными научными и образовательными организациями;

- использование института государственных контрактов в интересах инновационного развития производства;

- развитие отечественного производства с применением импортируемых инновационных технологий мирового уровня.

\section{Ссылки и примечания:}

1. Об утверждении государственной программы РФ «Экономическое развитие и инновационная экономика» [Электронный ресурс] : постановление Правительства РФ от 15 апр. 2014 г. № 316 : в ред. от 31 марта 2017 г. Доступ из справ.правовой системы «КонсультантПлюс» ; Об утверждении Стратегии развития медицинской промышленности РФ на период до 2020 г. [Электронный ресурс] : приказ Министерства промышленности и торговли РФ от 31 янв. 2013 г. № 118. Доступ из информ.-правовой системы «Гарант» ; Развитие фармацевтической и медицинской промышленности на 2013-2020 гг. [Электронный ресурс] : государственная программа РФ : утв. постановлением Правительства РФ от 15 апр. 2014 г. № 305 : с изм. и доп. от 30 дек. 2015 г., 31 марта 2017 г. Доступ из информ.-правовой системы «Гарант» ; Развитие фармацевтической и медицинской промышленности РФ на период до 2020 г. и дальнейшую перспективу [Электронный ресурс] : федеральная целевая программа : утв. постановлением Правительства РФ от 17 февр. 2011 г. № 91 : с изм. и доп. от 9 июня 2016 г. Доступ из информ.-правовой системы «Гарант»; Стратегия развития здравоохранения РФ на долгосрочный период [Электронный ресypc]. URL: http://www.rosminzdrav.ru/ministry/61/22/stranitsa979/strategiya-razvitiya-zdravoohraneniya-rossiyskoy-federatsii-na-dolgosrochnyy-period (дата обращения: 10.08.2017).

2. Развитие науки и наукоемких технологий - основа экономической безопасности России в XXI в. / В.А. Черешнев, В.В. Черешнев, Д.Н. Верзилин, Т.Г. Максимова // Экономика региона. 2008. № 3. С. 8-13 ; Сигов В.И., Верзилин Д.Н., Верзилин С.Д. Программно-целевое управление социальной безопасностью: концептуальный подход к оцениванию результативности // Журнал правовых и экономических исследований. 2015. № 4. С. 162-168.

3. Развитие фармацевтической и медицинской промышленности на 2013-2020 гг. ...

4. Методические рекомендации по оценке эффективности инвестиционных проектов: словарь финансовыхи юридических терминов [Электронный ресурс] : утв. Минэкономики РФ, Минфином РФ, Госстроем РФ 21 июня 1999 г. № ВК 477. Доступ из справ.-правовой системы «КонсультантПлюс» ; Райзберг Б.А., Лозовский Л.Ш., Стародубцева Е.Б. Современный экономический словарь : 6-е изд., перераб. и доп. / под общ. ред. Б.А. Райзберга. М., 2013. 512 с.

5. Аверина И.С. Эволюция и классификация феномена «хозяйственный механизм» // Вестник ВолГУ. Серия 3: Экономика и экология. 2012. № 2 (21). С. 12-16 ; Балашов А.И. Формирование механизма устойчивого развития фрармацевтической отрасли: теория и методология. СПб., 2012. 160 с. ; Богданова Е.Л., Ветрова А.А., Воронов Е.П. Центры поддержки технологий и инноваций как инструмент повышения эффективности управления инновациями // Научный журнал НИУ ИТМО. Серия: Экономика и экологический менеджмент. 2015. № 2. С. 194-200 ; Кухарук А.Д. Содержание организационно-экономического механизма повышения конкурентоспособности предприятия // Вестник КемГУ. 2013. Т. 1, № 2 (542). С. 283-287 ; Маннапов Р.Г., Ахтариева Л.Г. Организационно-экономический механизм управления регионом: формирование, функционирование, развитие : монография. М., 2008. 352 с.

6. Методические рекомендации ...

7. Promoting access to medical technologies and innovation: Intersections between public health, intellectual property and trade [Электронный ресурc]. URL: http://www.who.int/phi/promoting_access_medical_innovation/en/ (дата обращения: 10.08.2017)

8. Горнак С.Ю., Чаргазия Г.Г. Информационные основы мониторинга процессов импортозамещения в инновационных отраслях российской экономики // Теория и практика общественного развития. 2015. № 12. С. 165-167; Максимова Т.Г., Кукушкин А.М., Шаныгин С.И. Статистика финансовой обеспеченности и результативности научной деятельности // Научный журнал НИУ ИТМО. Серия: Экономика и экологический менеджмент. 2013. № 2. С. 22 ; Развитие фармацевтической и медицинской промышленности на 2013-2020 гг. ...

9. Горнак С.Ю., Чаргазия Г.Г. Указ. соч. ; Максимова Т.Г., Кукушкин А.М., Шаныгин С.И. Указ. соч.

10. Верзилин Д.Н. Методические основы мониторинга угроз экономической безопасности при поставках товаров для государственных нужд // Вестник Санкт-Петербургского университета МВД России. 2012. Т. 53, № 1. С. 148-152.

11. Богданова Е.Л., Ветрова А.А., Воронов Е.П. Указ. соч.

12. HIV drug resistance report 2017 [Электронный ресурc] / World Health Organization. URL: http://apps.who.int/iris/bitstream/10665/255896/1/9789241512831-eng.pdf (дата обращения: 10.08.2017).

13. «Надо не законы штамповать, а увеличивать бюджет на борьбу с ВИЧ» [Электронный ресурс] // Vademecum. 2017. 26 янв. URL: https://vademec.ru/article/vadim_pokrovskiy-_nado_ne_zakony_shtampovat-_a_uvelichivat_byudzhet_borby_s_vich/ (дата обращения: 10.08.2017).

14. Социально-экономический мониторинг угрозы распространения ВИЧ/СПИД в Российской Федерации / В.А. Черешнев, Д.Н. Верзилин, Т.Г. Максимова, Е.В. Черешнева // Экономика региона. 2012. № 2 (30). С. 153-169.

15. Балашов А.И. Указ. соч.

16. Составлено автором на основе данных Единой межведомственной информационно-статистической системы (EMИCC, www.fedstat.ru). 


\section{References:}

Averina, IS 2012, 'Evolution and classification of the phenomenon of economic mechanism', Vestnik VolGU. Seriya 3 : Ekonomika i ekologiya, no. 2 (21), pp. 12-16, (in Russian).

Balashov, Al 2012, The formation of the sustainable development mechanism for the pharmaceutical industry: theory and methodology, St. Petersburg, 160 p., (in Russian).

Bogdanova, EL, Vetrova, AA \& Voronov, EP 2015, 'Technology and innovation support center as a tool for improving the efficiency of innovation management', Nauchnyy zhurnal NIU ITMO. Seriya: Ekonomika i ekologicheskiy menedzhment, no. 2, pp. 194-200, (in Russian).

Chereshnev, VA, Chereshnev, VV, Verzilin, DN \& Maksimova, TG 2008, 'The development of science and high technology is the basis of Russian economic security in the 21st century', Ekonomika regiona, no. 3, pp. 8-13, (in Russian).

Chereshnev, VA, Verzilin, DN, Maksimova, TG \& Chereshneva, EV 2012, 'Social and economic HIVIAIDS threat monitoring in the Russian Federation', Ekonomika regiona, no. 2 (30), pp. 153-169, (in Russian).

Gornak, SYu \& Chargaziya, GG 2015, 'Information support of import substitution monitoring in innovative sectors of the Russian economy', Teoriya i praktika obshchestvennogo razvitiya, no. 12, pp. 165-167, (in Russian).

HIV drug resistance report/ World Health Organization 2017, viewed 10 August 2017, <http://apps.who.int/iris/bitstream/10665/255896/1/9789241512831-eng.pdf>.

Kukharuk, AD 2013, 'The content of organizational economic competitiveness mechanism at the enterprise', Vestnik KemGU, vol. 1, no. 2 (542), pp. 283-287, (in Russian).

Maksimova, TG, Kukushkin, AM \& Shanygin, SI 2013, 'Statistics for the financial security and the effective research activity', Nauchnyy zhurnal NIU ITMO. Seriya: Ekonomika i ekologicheskiy menedzhment, no. 2, p. 22, (in Russian).

Mannapov, RG \& Akhtarieva, LG 2008, Organizational economic mechanism of regional management: formation, functions, development, monograph, Moscow, 352 p., (in Russian).

Promoting access to medical technologies and innovation: Intersections between public health, intellectual property and trade 2017, viewed 10 August 2017, <http://www.who.int/phi/promoting_access_medical_innovation/en/>.

Reisberg, BA, Lozovsky, LSh \& Starodubtseva, EB 2013, Modern economic dictionary, 6th ed., Moscow, 512 p., (in Russian).

Sigov, VI, Verzilin, DN \& Verzilin, SD 2015, 'Management by objectives in relation to social security: a conceptual approach to evaluating performance', Zhurnal pravovykh i ekonomicheskikh issledovaniy, no. 4, pp. 162-168, (in Russian).

Verzilin, DN 2012, 'Methodical foundations for the economic insecurity monitoring in the supply of public goods', Vestnik Sankt-Peterburgskogo universiteta MVD Rossii, vol. 53, no. 1, pp. 148-152, (in Russian). 